\title{
Prosperity through Tourists in Lamjung District: An Anthropological Outlook
}

\author{
Badri Nath Bhatta, \\ P K Campus, Kathmandu \\ badribhatta97@gmail.com
}

\begin{abstract}
The study areas of anthropology have been growing day by day. Therefore, it has concerned with various parts of society such as sanitation, water supply, poverty, traditional practice, folk music, tourism etc as multidisciplinary areas. In fact, anthropology and tourism are co-evolutionary process in the path of their developments because they help each other in many ways. Traditionally, tourism and tourist are major anthropological sources of information to analyse the situation of then and present society and culture. Similarly, tourist can enjoy visiting any places by learning anthropological knowledge and findings. Methodologically, this is based on field observation, interview and other secondary sources to analyse the scenario. After the introduction of democracy in Nepal, she has been opened to outsiders. As a result, Sir Edmund Hillary as foreigner visited Nepal. Hillary with Tenzing Norgy Sherpa successfully climbed the Mount Everest in 29 May, 1953 at the first time. Then the glorious name of Nepal has become famous in the world. The tourism industries have been initiated from Thamel, Solukhumbo, Pokhara and then gradually extended in other parts of the country. Tourism at present period has popular pursuit in several parts of Nepal involving from hotel, lodge, guide, restaurant, expedition to home stay and other businesses. Lamjung has own identity in tourism perspective. The Ghalegaun is famous in SAARC level as model program for the home stay concept. From perennial snow peaks, biodiversity to natural forest of rhododendron in mountain to hill parts in the north and plain narrow valley in the south to develop cultural lives can be observed there. Lamjung has been enriched in different culture, fest and festivals. Paudure dance among the Kumal, bees hunting in steep slope rocky hills to Rodi in the Gurung have their own identity popular in the district.
\end{abstract}

Key words- tourism, bee hunting, smokeless industry, Paudure dance, Thorong La pass

\section{Tourism in Anthropological Outlooks}

Having multidisciplinary nature in the systematic study of tourism, anthropologists as others recently began to study in such field. Tourism is the important component as well as subject- 
matter to carry out anthropological studies. Therefore, anthropologists pay attention to the study of the tourism because it is the one of the factors influencing to the diffusion of culture from place to place. Likewise, tourism has interrelationship with society, culture and people. Behinds, anthropology can help tourist and tourism to provide required knowledge and information to make plan and visit from place to place. Despite the close relationship each other, Seymour -Smith (1986) states that anthropological studies indicate that people and existing traditional cultures are found affected by tourism to "a greater and lesser degree". In some case studies, it is also found that tourism as industry or business can make drastic change through "economic and social circumstances". Thus, at the one side, tourism can help to increase economic benefits, maintain higher lifestyle to certain groups of people, provide jobs to people in general and distort local history, arts, skills and styles badly at the others. In spite of good and bad aspects associated with tourism, it is the main sources of income and opportunities in Third World countries like Nepal.

Burns (2004) showing their relationship each other has analyzed tourism and anthropology have unavoidable relationship because there are many similarities between ethnographer and tourists. After the study of tourism, anthropologists can get new vision to address the theoretical challenges for anthropological research and it helps to develop multi-disciplinary thinking in its fields. Therefore, she argues that anthropologists can involve studying the tourism for the analysis of the positive and negative impacts in host communities after the arrival of tourists and promoting the natural and cultural heritages and their potentiality in the given areas. Both Burns (2004) and Seymour -Smith (1986) have shown their concerns on tourism impacts ignoring tourism history and its original circumstances.

Additionally, Stronza (2001) begins his writing on the article that tourism and anthropology are closely related fields from many ways where he has expressed tourism can help getting the answers of many different questions as asked by anthropologists. He also focuses on understanding of the origin of tourism and analyzes its impacts as the objectives of this study. He says "For anthropologists, tourism can be a lens through which to explore issues of political economy, social change and development, natural resource management, and cultural identity and expression". He concludes that different motives play vital roles for the origin of tourism in host areas and it has both positive and negative impacts to both host and recipient communities. Further he quotes the views of Turner (1974):

“...Tourism has some aspects of showbiz, some of international trade in commodities; it is part innocent fun, part a devastating modernizing force. Being all these things simultaneously, it tends to induce partial analysis only..." (p. 261) - Victor Turner, 1974 as cited by Stronza (2001).

Stronza argues eco-tourism has been recently developed as alternative form in this field while Nahman (2016) says reproducing travel is not new but due to cross- border egg donation and surrogacy, reproductive tourism in anthropological field is certainly new area for the further investigation. Now, ecotourism has been popular to change the community through socioeconomic and environmental benefits as possible. Supporting this study area as new, Nash 
(1981) states that anthropological study of tourism is still recent or in its infant stage though enough works have been done being such status. He states it has various reasons - it is the action of bold and brave, it is frivolous area of culture, and it is as something modern and so forth. It is also said that anthropologists had less aware in this field. As a result, it has been delayed to acquire anthropological legitimacy on such study. Moreover, this paper tries to define tourism as a variety of leisure activity where tourist is a person at leisure that travels from place to place and of tourism. In reality, tourism sometime involves an encounter/conflict between tourist and host- societies when anyone does not understand from one to other or show vested interest. It is complex to get the similar types of socio-culture situation everywhere and its consequence cannot be similar from society to society. However, it is essential to find out causes and consequences of tourism from host to recipient society/countries in particular. However, this study concerns to explore how and when tourism is introduced and what types of natural and cultural heritages are found in Lamjung District for showing prosperity through tourism.

Anthropologically tourists are considered as the agent of cultural change. They collect the data and information from one society and compare and explain to other societies in comparative ways. Therefore, tourist is the one of the sources of anthropological analysis. Anthropologists can explain the context of their different theories by support such source - including pilgrimages, businessmen, travellers, missionaries and many others. Anthropology has important contribution to offer to the study of tourism, especially through a neo- traditional approach that includes the basic ethnography and its national character where participant observation play main role as research instrument to garner the required data. Different models including the acculturation model assert that the tourism is only element in cultural change (Smith, 1980:15).

Some native scholars have crucial role to study in such area. Among them, R R Kunwar (2002) has made some significant contribution in the practical study of anthropology of tourism with its etymological meanings. The word 'tour' (the movement around a circle) as prefix is combined with suffix 'ism' and 'ist' (doctrine/principle having practices in a person) and developed as tourism or tourist and its meaning. In total, this means 'the action of movement around a circle' or 'one that performs a given action'. He has explained at first the setting of Sauraha to extension of tourism there in detail way specially influences to Tharu cultures and their activities. He has mentioned his views on community forest, tourism and development, and other components focusing on what influences on their lifestyles after the tourism extensions there. According to him, tourism in Sauraha has important contribution to develop modern Sauraha as tourist centre in Chitwan in particular. At the one side, some non-Tharu people migrated there to involve in their economic businesses - hotels, lodges, guides etc. where local Tharu youths at first began to sell their original lands to outsiders. The result at the one is positive to get large sum of money and some Tharus misuses from diamond to iron at the other. This means that some outsiders can earn more properties by buying the Tharu indigenous lands than local Tharu staying there. Ironically, Tharus misuses the money as iron, i.e. spend the money for enjoying alcohol (p. 104). The original Tharu dominated areas then became mixed with non-Tharu people area. In reality, non-Tharus are getting direct benefits from tourism than Tharu, Sauraha is becoming there a village of heterogeneous groups and Tharu cultures have been to disturb for the protection of its traditional originalities. For instance, it has affected the original cultures of the Tharu and some 
original identities of Tharu such as curio, indigenous pots and utensils including dress are begun to sell unplanned way to foreigners and made them in endangering stage at all. As a result, the originalities have been distorted now in reality.

Tourism has been raising awareness through cultural tourism and bringing different impacts in the life of people which has been in the area for anthropological study. It has various subfields like anthropology of tourism. Anthropology of tourism has developed various concepts in tourism studies. There are some scholars such as Nelson Graburn, Dennison Nash, Erik Cohen, Mac Connell and others inclining to this field. As a sub discipline, anthropology of tourism is the study about the origin of tourism with its impacts in local life, how and what changes takes place in the given culture through the arrival of outsiders. Similarly, it focuses on locality, identity, political economy and development in the form of globalization from host to recipient societies critically (Kuwar, 2006:114-120).

Cultural tourism is also popular field of anthropology. The concept of cultural tourism was emerged in 1970s. Later, UNESCO recognized this form of tourism in 1976. Kunwar (2006:115) said cultural tourism; by definition is a force for cultural preservation. After the movement of tourism from place to place, the prevailing culture may be affected. That is why cultural tourism assists to protect existing culture through different activities such as awareness program, emphasis to native habits and life style, promote local arts and handicrafts. Valene L. Smith (1989) as quoted by Kuwar (2006:116) defined cultural tourism slightly different way, as the absorption of tourists through such phenomena as house styles, crafts, farming equipments and dresses. Therefore, cultural tourism helps to protect existing cultures and promote the activities for their preservation.

The literatures in anthropological view make clear that tourisms are the major agent of cultural borrowings from place to place. Travelling from place to place emerged the view of tourism with economic significance globally. After the innovation of overseas extension, journey took place all over the world as a tourist. Therefore, tourism has own past history and developed in present as organized way differently by introducing new areas/fields. Sharma (1995) in this regard compared the primitive and modern tourism and portrayed,

“...Travelling has become a global phenomenon, and industrially advanced countries of the west, taking their national far and wide, visiting exotic places, enjoying their unique natural and cultural heritage and getting all the fun and adventure out of it. Modern tourism, however, has gone beyond this early innocence. It has become a much more organized, professional and hard-headed business. In Third World countries such as Nepal, tourism is regarded as a top money spinner and an extensively economic preoccupation..." (p.1)

Tourism in modern period has been significant source of the country's income. P R Sharma (1995) rightly said tourism in Nepal, therefore was classed under industry in the very early stage of its development. Today it is looked on as Nepal's single most prized "economic commodity" the selling of which earns the country its valuable foreign exchange and generates a good income 
in the form of revenue. Employment generation is also other economic basis through tourism in the country (Seymour- Smith, 1986:279).

In this theoretical background, I realized that there is still lacking the basic data of Lamjung district relating to prosperities through tourism including its natural, socio-cultural scenario wherein I planned to apply anthropological knowledge associating in overall career in my life. Some few literatures of then DDC, NTNC, ICIMOD and others are found. However, it has much prosperity to promote tourism in general and to support the local people and others in employment and income generating activities as its impact in the district in specific sense. Therefore, the objectives behind the study for this paper are to prepare theoretical linkage between anthropology and tourism, to highlight the origin and general scenario of Lamjung district in tourist sector and to portray the natural and cultural heritages of the district for showing prosperity through tourism. During study period, I administrated general field observation, interview and other secondary sources as the research instruments. During field visit to collect the basic data, I have visited and observed in different parts of district like Tinpiple, Rainaskot, Besishahar, Khudi, Ghalegaun, Gilung, Bhorletar etc and held some interviews with key informants of Gurung, Ghale, Kumal, Newar, Chhetri and other communities, In this background, the author has attempted to prepare a brief profile of Lamjung particularly tourism sector.

\section{Efforts in Tourism in Nepal}

The scope of anthropology has been growing year by year. Like tourists, anthropology based on ethnographic study makes field based travelling from place to place. Despite so, they have closely related. Anthropological discussion on tourism began in Europe in the 1930s while in USA in the 1960s. The work of Smith (1980) on tourism is famous in anthropology in USA (Montero, 2014). Though some of the foreigners from westerns especially Britain began to visit in Nepal when British traders and businessmen arrived in India associating East India Company. Tibetan and Chinese including Indians visited in Nepal during Lechchavi and Malla periods also. When Nepal was free from 104 year Rana anarchism, she was opened to foreigners, Edmund Hillary and Tenzing N Sherpa first climbed Mt. Everest in 29 May, 1953 though mountaineer expedition efforts were begun earlier. Consequently, the name of Nepal has extended all over the world as mountainous country and begun the tourism at first Mt Everest area, then Kathmandu (Thamel) and Pokhara. However, the study of tourism might be initiated in 1990s when ICIMOD hired Mr. Sharma in 1994 for preparing discussion paper on culture and tourism in Nepal (Sharma, 1995). Local entrepreneur Ram Prasad Shrestha as key informant states that after the introduction and potentiality of Annapurna Circuit in the book of late Dr. Harka Gurung in 1970s, tourist route was initiated to western tourists in Lamjung from Dumre, close link point with Prithwi Highway to Manang, Thorong La pass to Mustang and Pokhara and vice versa. Since 1985, tourism development has been gradually extended in the district.

In Nepali context, tourism is recognized as smokeless industry to earn more employment and income. Tourism development and its importance are the recent phenomena in Nepal. First Fifth Plan (1956 to 61) made the provision of tourism development for the first time in the country. After introducing the first policy, Tourist Development Board was established in 1957 based on Development Act, 1956. The Board contributed to the creation of Department of Tourism 
in 1961 under then Ministry of Public Works, Transport and Communication. Subsequently, the Department was transferred into the wing of Ministry of Commerce and Industry. In 1977, Ministry of Tourism was set up. Later it has been developed as Ministry of Cultural, Tourism and Civil Aviation. Due to the adequate possibility in tourist sector throughout the country, the department could not make ambitious and effective plans and policies in this sector (Sharma, 1995).

\section{The Settings of the Study Area}

Situated in the lap of Annapurna, Baudha, Manaslu, Himchuli and other Himalayan peaks, Lamjung is a mid-hill district of the country and has nearly round shaped in the map of Nepal. Geographically, it is situated in the middle of Gandaki zone. It lies in the Western Development Region of Nepal. In present restructuring in Nepal, this area falls in Gandaki province. Beshishahar is the district headquarters of the district. Naturally it has so many resources from snowline in the northern part to narrow river valley /belt in the southern part. In history, Lamung has its own position during Baise ra Chaubise Rajya (22 and 24 tiny states). From the ancient period, Lamjung has made significant status in the country. During the period of Baiese ra Chaubise Rajya, Lamjung was smaller in population than Gorkha, and Tanahun however, it managed at first cannons to attack the opposite states where such cannons were not available at then other states. Once it is historically said there was also a court in Tarku, near Sundarbazar during Rana period handling the local issues/cases in that areas and it's peripheral parts. Lamjung was ruled by Ghale to Shah Dynasties in its history (Thapa, 2007: 2-3). Therefore, Lamjung is powerful tiny state during historical period and it has prosperous in its history and observable scenario in the country.

During field observation it is found that Bahundanda, Khudi, Gilung, Bhorletar, Ramgatar, Kunchha, Duradanda, Sundarbazar, Bhoteodar, Chiti, Manjang Sera, Gauda, Tinpiple, Alkatar, Borangkhola and Bichour are sub stations and emerging semi urban areas of the district. The district surrounds Manang to the north, Tanahun to the south, Gorkha to the east and Kaski districts to the west. It covers an area of about 1,694 sq. km. From north to south and from east to west district stretches over a maximum distance of approximately $50 \mathrm{~km}$ (ICIMOD, 1996:3). Major parts of the district cover Mahabharat Range to the high Himalayan peaks. Some parts to the west and south of the district are narrow river valley/plain as Tar and Beshi (plain areas). Some of the plain and flat areas are Rainastar, Tarkutar, Handetar, Ramghatar, Karaputar and Bhorletar where local streams and Kholas such as Champabati (Chepe), Paundi, Risti and Midim irrigate most of the farmlands respectively. The narrow basins of the Marshyagdi river from bottom belt of Bahundanda to Bhotewodar, Rudi, Midim, Naudi, Paudi, Dordi and Chepe Kholas in the district have also made narrow belt fertile land. In reality, these plain and flat areas are the backbone of the district as Tarai of the country.

Since 1989, International Center for Integrated Mountain Development (ICIMOD) has developed a strong capability in the fields of Geographical Information System (GIS) and Remote Sensing (RS) Technology through its Mountain Environment and Natural Resources' Information System (MENRIS). With the support of ICIMOD, a field based report was prepared about Lamjung (ICIMOD, 1996). This report includes the outlines of the project, information on infrastructure, 
services, and different variables of population at the then VDC levels, land system and so forth (ibid, p.2-6). Among them, the major land system is outlined as follow.

Table: 1 Land System of Lamjung District

\begin{tabular}{|l|c|c|}
\hline \multicolumn{1}{|c|}{ Land System } & Area (Sq. Km) & Percentage \\
\hline Middle Mountain Region & 720 & $42.5 \%$ \\
\hline High Mountain Region & 665 & $39.2 \%$ \\
\hline High Himalayan Region & 309 & $18.3 \%$ \\
\hline Total & 1694 & $100 \%$ \\
\hline
\end{tabular}

Source: ICIMOD, 1996

The Land Resource Mapping Project (LRMP) had classified the whole country in the 1980s and had established a new land system legend differentiating between five physiographic regions; the Terai, the Siwaliks, Middle Mountain, High Mountain and the High Himalayan where geology, climate and land pattern and land used practice are different. In Lamjung, major part of the land system (42.5\%) is middle mountain region followed by high mountain region (39.2\%) and high Himalayan region $(18.3 \%)$ based on table -1 .

\section{Agriculture and other Development prosperities}

Nepal Tourism Board highlighted that one of the trekking route of Annapurna region is Lamjung. As Pokhara, it would be either starting or ending point of the trekking in Annapurna circuit. Hence, the prosperity through tourism in the district is quite bright and useful. Tourism along with agriculture is the backbone of the district. The field visit indicates that though most of the north parts are covered by perennial snowline; the south narrow belt is useful for agriculture. In Madhi (a big and massive extended long plain in high altitude of the northern part as high altitude meadow) of the district, base camp, scene of the mountains, floras and faunas with natural beauty are observable. Research activities in high altitude for different crops, day to day cultures of high altitude people as well as other prosperities may have been undertaken in future.

Rainastar irrigation project (RIP) situated in low belt area is one of the larger irrigation projects in the hilly part of the country. In the Chepe Khola watershed area, the project covers plain areas of Rainas municipality with $21 \mathrm{~km}$ (canal under operation is only $17 \mathrm{~km}$ ) in distance from head to tail in the southeast belt of the district. The total command area is 850 ha (Department of Irrigation, 2005). After the completion of the project, it has played a vital role in order to minimize poverty in the district in general and the catchments area in particular. Upon the completion of the RIP, paddy, maize, wheat and other crops including vocational and off seasonal farming thrice a year have been growing there. Along with Rainastar, other Tars (narrow plain belt) such as Pangrephant, Handetar, Ramghatar, Bhorletar and Karputar are also irrigated and fertile area for the food supply in the district. Having such narrow plains with irrigation facilities, the district is benefitted in agriculture. Sheep farming are keeping in Madhi and high altitude areas. Likewise, horticulture and agronomy are being flourished in the irrigated area of the district. Recently, the district is self-dependence on fish supply and growing coffee, banana and vegetable productions. 
In field visit and discussion with key informants, it is clear that Marshyangdi River flows in the centre of the district that is recognized as a useful river for power generations in the country. Middle Marshyangdi and lower Marshyangdi have supplied power to the country. Recently the next projects in upper Marshyangdi in north of the district is under construction. Ngayadi hydro has begun the production and listed in share market. Tourists are found enjoying with the rafting in Marshyandi and Madi rivers. Similarly, small Kholas like Nyadi, Khudi, Dordi and so forth are at present utilizing for small power plants. Feasibility studies in different parts of Chepe Khola reveal that there are also possibilities of small power plants. The district has still further feasibility of power station in other rivers and steams/flood ways. Perennial snow peaks, high altitude plain as Madhi, green forest, hilly terrain, narrow valley, vertical fountains and hilltop are also natural beauty of the district. Most of the colourful rhododendrons and others natural flowers are found seasonally at the north belt with perennial snow covered peaks, high altitude plain and hilltop. Narrow valley at the south belt with farmland represents really the heartfelt natural beauty of the district. Therefore, the study area is a land of extremes- the climate ranges from subtropical in the south to arctic in the north parts of the district. The physiography includes fertile alluvial plains below 500 metres above sea level and very rugged, permanently snow covered peaks (ICIMOD, 1996:31-35).

\section{Socio Demography}

In the census of 2001 , the total population of the district was $177,149(83,406$ males and 93,743 females) with 36,525 households. In 2011, the total population $(167,724)$ is found decreasing because of foreign and internal migrations for employment and other opportunity. The total Household was 42079 with males (75250) and females (92474) populations. The sex ratio is 82.68 and $\mathrm{HH}$ size is 3.99 (CBS, 2011).

The table 2 (see Annex-1) indicates that Gurungs (31.25\%) are in majority followed by Kshetris (15.99\%), Brahmins (12.75\%), Kamis (8.63\%) and Tamangs (7.23\%). Duras, Kumals and Thakuris are the minor groups in the district. Muslim/ Chureta, Rai, Gaine/Gandharva, Chepang and some Tarai groups are categorized in other groups (CBS, 2011). Earlier, the district is divided into 61 VDCs. At present, these VDCs are merged into 8 local levels based on the state new restructure as stated in Constitution of Nepal, 2015. Among them, four are emerging municipalities in middle and southern parts while remaining four are rural municipalities in northern parts of the district based on fieldwork, 2017.

It is interesting to study the ICIMOD report, 1996 categorizing then VDCs based on caste/ethnic domination. As per the data surveyed by ICIMOD in 1995, then 7 VDCs (Gaunda, Ghermu, Pachock, Bhujung, Pasgaun and Uttarkanya) are dominated by the Gurungs for more than $80 \%$ followed by the Chhetries in 2 VDCs (Beshishahar and Chadisthan) and the Brahmins in 2 VDCs (Chandreshwor and Duradanda) for more than 50\% each. The Tamangs are spread throughout the district and constitute a major group in Bhulbhule, Khudi, Phaleni, and Ilampokhari accounting for more than $25 \%$ of the population. The Newars are minority groups; nevertheless they are dominated for more the $15 \%$ population in Swamivanjyang, Ramga, Suryapal and Tarkughat VDCs. Likewise, the next minority group is the Duras which are concentrated in very fewer VDCs like Neta and Sindhure for more than $75 \%$ of the total population. Among the Dalit groups, 
the Kami, the Sarki and the Damai are scattered throughout the district, however more than 20\% of the Kami are dominated in Ghanpokhra, Gilung and Hiletaksar VDCs while more than 10\% of the Sarki are in Dhamilikuwa, Tarkughat, Udipur and Suryapal VDCs and the Damai are minority everywhere. The Gaine, a very minority group of Dalit is found in very fewer VDCs. Very minority group like the Bhats are one-third in Bansar VDC. The next minority groups like the Kumals are in some very southern VDCs of the district such as Chakratirth, Sundarbazar, Parewadanda and Ramga VDCs. They are more than 20\% in Ramga (ICIMOD, 1996:16-17).

In accordance with conventional settlement pattern of the district, it was traditionally found that the settlements are dominated by caste/ethnic groups but now mixed pattern is mostly found. For instance, some north parts are perennial snowline while the rest parts of the district are practicing for the human settlements. In the top of the hill, it is conventionally habitat of the Ghales, the Gurungs, and the Tamangs/ Bhotes groups of people. In the middle of the Mahabharat range, mixed settlements are in practice where the Duras, the Magars, the Sanyashis, the Ghartis, the Dalits (Kami, Damai, Ghaine and Sarki in the context of the study area) and the Brahmans/ Chhetris live. In the lower part of the hill and narrow valley of the south of the district, the autochthonous group likes the Kumals and Majhi are found. After the Malaria control, most of the groups who reside in the top and middle hill are migrated into lower and narrow valley of the district. Therefore, the lower part of the district at present is found crowded where fertile land for subsistence farming has been massively occupied by local dwellers for house places.

In social sector, 70.9 ages is the life expectancy in years while $71 \%$ people can read and write as literacy rate and $16.8 \%$ populations are in poverty ( $23.48 \%$ in national level) of the district (CBS, 2014). There are several public secondary schools, higher secondary schools and some public and private colleges. In general observation, it is found that agriculture campus is also established in Sundarbazar where several new technologies based on agriculture and animal science can be observed. Likewise, people of the district including its peripheral neighboring districts can get the health services from district hospital in Beshishar, district headquarter with the support of United Mission to Nepal. In the context of economic sense, majority population involve in agriculture with forestry. In trade and industrial outlook, there are different emerging hill towns in the district. As the information from key informant interview, cottage and small industries based on different raw materials are found there. They are Lokta as Nepali kagaj (hand-made paper), woollen materials (Bakhu, Radi Pakhi, and carpet), pot making, mining and quarrying, cereal crops, ghee, local fruits, herbals and fishing, construction materials (gravel, sand etc), trekking and tourism, hotels and restaurants and so forth. Recently, it is declared that the district is self dependence in fishing. Coffee and green vegetables are also massive production in the district. During the study period, the business persons in Besishahar state that one hotel with 4 star standards is established and they claimed that some of the 12 hotels with various rooms have the availability of continental including Chinese foods in the district centre where more than 200 to 250 tourists could be stayed in one night there. Likewise, various other hotels and restaurants are also available there with standard facilities though they are not star hotel. Across the district, the key informants claimed that luxurious hotel and other tourism facilities are available in the trekking route of Annapurna circuit in Lamjung and Manang districts. A tourist information centre is also available in Besishahar. 
A link road between Dumre to Beshishahar has made easier access to the district however the district has partial earthen road network also. The earthen rural and agricultural roads are from Ramga-Bhorletar- Gilung, Chepeghat-Tinpiple- Borankhola, Paudi- Moharia- Pyarjung, Paudi/ Bhoteodar- Sundarbazar - Kunchha and Duradanda, Kunchha-Neta- Sindure -Baglungpani Bhujung, Beshisahar- Baglungpani- Bhujung, Beshisahar-Khudi-Manang and so on. Sometime, trekking is also required for the access to remote and hilly areas. Mule and porter were the most effective means of transport in remote and rural areas. Presently they are replaced by bus, truck and other vehicles.

\section{Natural and Cultural Heritages}

From the tourist perspective, the fieldwork indicates that Lamjung is also famous historical and cultural places. Most of the western and Indian tourists would emphasize to visit Annapurna and Thorong La pass via Lamjung as circuit. The district is rich in natural and cultural heritages. One can enjoy snow coverage mountain peaks, green forest, vertical fountains, unique honey hunting technology under slope rock, rock garden, home stay to domestic visitors, different types of cultures and irrigated farmlands etc. In reality, these are the main tourism affluences of the district anthropologically. Realizing the fact, ACAP has been implemented in the northern belt of the district. It has carried out some activities based on eco-tourism as Stronza (2001). Lamjung festival is yearly organized for the extension and dissemination of natural and cultural heritages of the district. Tourists can enjoy with original Gurung, Dura, Kumal, Brahmin and Kshetri cultures and traditions in the district. Key informants said that Lamjung is a district, which is recognized as the homeland of the Duras. The famous name of Duradanda is derived from the Dura ethnic group. At present, the Dura are only in the peripheral area of Duradanda. By account of modern migration process, the key informants state that some Dura people are found in Tanahun, Kaski, Chitawan and even Ramechhap districts of the country. The Rodi system is unique and popular culture among the Gurungs and the Duras (Bista, 1976: 84 and Bhatta, 1999: 4). However, Gurung key informants express that such types of culture are presently endangered. Ghatu dance among Gurung communities during the period of Lord Buddha Memorial Day (Full moon day of the Baishakh [April and May] month) can be observed. Thadobhaka (a traditional style of the song) especially led by Vedikharke Sahila was/is very popular in Lamjung culture, now in record only. Some of the other singers are famous in the country. They are late Deu Bahadur Dura, and Bima Kumari Dura of Thuloswara and Raju Pariyar of Gausahar. Likewise, Paudure dance is also popular among the Kumal people during Tihar festival. Panche Baja, Balun, Khaijedi and Teej dances are generally organized throughout the district.

Kumal informants have expressed their views on their traditional cultures. During winter, it will be also interesting to observe and participate in Jalkanda Khalne (the Kumal ethnic groups used to collect fish by standing in a chain across the river and trap the fish into net while new comers arrived in their community) with Kumal people on the bank of Chepe, Naudi, Paudi, Risti Kholas and Madi Rivers (Bhatta, 1995:31). Now-a-days, such types of culture have been also endangered. It is also possible to visit the brave elderly Gurung and Kshetri males and sharing their roles and experiences in the different wars and battlefields all over the world. In Mohoria during field visit, it is also observed the statue of the brave Sardar Bhakti Thapa is erected who fought at the age of 70 with British army in Deuthal of Malaun fort in present 
Uttarakhanda of India. Singh Bahadur Thapa, Mayor of Rainas Municipality said that this is known as Bhakti Thapa Park with establishing some gardens of local trees and flowers around the statue. Local leader and key informant Purna Bahadur Gurung of Kudule emphasized that the home stay program at Rainaskot has been extended from Kotgau to larger Gurung community of Kudule where community people have developed some tourism infrastructures such as rural road, protection of historical reminds of Rainaskot, construction of park, trial paragliding fly, community building etc in the supports of different hands like local municipality, Gandaki province and federal ministry of tourism.

At present, Ghalegaun is famous for rural tourism with paying guest system. When I was in Ghalegau, each woman involves welcoming us like other tourists by providing Foolmala (flower and local garlands) and Khada (a silky piece of cloth putting on the neck in order to provide hospitality in their localities). At the same time, the women manage to new comer/visitors by dividing them in neighboring houses for night rest and by servicing local foods and beds and enjoy them through singing and dancing during late evening as a model program even in SAARC level. Prem Ghale as chief of this concept remarks that Ghalegau model home stay program has presently extended to $34 \mathrm{HHs}$ in this community where 300 visitors can easily stay there for accommodation. The program has been recently planned as smart tool so that the visitors can get significant, meaningful and reasonable services there within specific time bound. He adds only internal tourists for refreshment in Friday, Saturday and even other public holidays visit and stay night camp there. Paying guest system is known as home stay using recently in tourism sector. New and innovative concepts would be next possible in order to promote tourism in the different parts of the country and help to succeed the tourism industries as expectation. Homestay is generally understood as night camp for food and sleep adjusting with local environment as available in paying system for certain periods- visiting, studying and other purposes. Cambridge Dictionary states home-stay as "a type of holiday or visit in which we can stay in the home to the person who do not know". To generate local income, it is new type of hotel or lodge based on local sources with considerable rate. After the success of model home-stay in Ghalegau, key informants add that this practice has been extending in Kaulepani, Simrung and lately in Rainaskot village in the district and so forth. Various local tourists for day long or night pass are visiting and staying in such home-stay and helps to promote the internal tourism there.

During study period, it is found that the honey collection of wild bee at the very slope under rocky hill through the long rope and simple but long ladder is also wonderful skill among the Gurung of Dudhapokhari, Simi/Tanje and Ghermu areas. Such type practice is known as honey hunting. It is also recognized as an original cultural practice in the district. Few years ago, then District Development Committee, Lamjung proposed and executed a new plan (training and some other supports) how to extend the importance of this indigenous technology for its promotion, the exploitation available local resources and relate it with tourism prosperity. Modern education and appropriate training on bee protection, honey hunting etc. can play significant role for its protection and promotion for the year to come. Kamsarki Gurung of ward-5 in Marshyangdi Rural Municipality informed that the local youth in Khanigaun has initiated, developed and promoted rock garden by reshaping and connecting the huge stones and rocks situated locally and making initiative to visit the local tourists there at present. Hence, innovative programs are 
begun to promote tourism in the district. Mankali Gurung cum Kasi of Marshyangdi -5 remarked 'it makes our village as new destination point in future'.

Field observation reveals that Raksiko Bottle Bat Pahunalai Swagat Garne (the practice of hospitality to the new comers with local drink) with singing and dancing during evening of Gurung and Dura communities and pottery making of Kumal are also original cultures of Lamjung. Woolen blanket, carpet and Nepali paper are the traditional industries in the district. Missershchmidt (1978: 152) stated that some Gurung communities such as Ghanpokhara and its surrounding areas of Lamjung have the practices of Dhikur (traditional economic organization) as Thakalis of Thak Satsai. The Dhikur is rotating credit association as cooperative at present. Now such traditions and practices are not found extending its neighboring communities and are being endangered. In the districts, mountain peaks, lakes (Barahi pokhari, east and west Dhudh pokharis both in the sources of Madi and Chepe rivers), Hydro- power stations, rural market area (Beshisar, Chiti, Khudi, Bhulbhule, Bahundanda, Bhateodar, Sundarbazar, Tinpiple, Borangkhola, Kunchha, Sotipasal and Bhorletar) are some observable sites. Rainaskot, Moharia, Bharte, Gaunda, Ilampokhari, Gaunshahar, Puranukot, Khudi, Bhulbhule, Ghalegaun, Pasgaun, Bhoje, Tamu, Chiti, Phaleni, Turlungkot, Duradanda are some historical places.

Similarly, it is also found that the district is culturally and religiously enriched. Lamjung Kalika, Turlungkot Kalika, Utarkaya temple, Narayansthan, Udipur Kalika, Karapu/Isaneshwor Mahadevsthan, Rainas Kalika, Ilampokhri Devi are religiously famous sites of the district from Hindu practices. Likewise, some of the famous Gumbas in Chandidanda and other areas from Buddhist philosophy are there. Some Churches are begun to establish in some areas also. Some local Hat Bazaars (rural fairs and festivals) in the different parts of the district are also occasionally observed. Karaputar during Mahashivaratri, Turlungkot during Baishakh Purnima, Gaunshahar during Baishakh Purnima, Tarkughat recently in Paudi during Thuliekadashi festival, Chepeghat during Maghe Sankranti, Ilampokhari bazaar/fairs during Baishakh Purnima / Ashitirtiya, Kunaghatbazaar during Thuliekadashi and Dudhapokhari pilgrimages in the both sources of Madi and Chepe rivers during Janai Purnima in the district are very popular for the mass assembles in its peripheral areas. Visiting rural hat bazaar, historical and cultural heritages of the district can enjoy Indian and western tourists.

\section{Educational Implications}

Tourism has been important from educational perspective considering its economic contributions at present Nepal. Both formal and informal education programs have supported tourism and hospitality management in Nepal. Government has established Nepal academy of tourism and hotel management (NATHM) four decade ago in 1976 for hospitality education through practical approach. Tribhuvan University has recently developed and implemented a new course for hotel management. Similarly, different efforts have been made in private sector to extend the training covering tourism, hospitality, guides, trekking and other areas for well development of tourism in the country.

Influence of ACAP for Education and Conservation- After the introduction of Annapurna Conservation Area Project in Lamjung, Prem Ghale, chairman of Kloswothar Rural Municipality 
states that district people especially in project areas have been educated and aware for the nature conservation and change local people's lifestyle because the major concern of ACAP is nature and bio-diversity conservation through people participation. ACAP's documents clarify it does receive no grant of government but has been granted the right to collect the entry fees from the trekkers and tourists. Focusing on such activities, it has coverage the then 8 VDCs in northern part (now many parts of Kloswothar and Marshyandi Rural Municipalities and some few parts of Besishahar Municipality) of the district. After the program, it is expected that the local cultures, arts and traditions, flora and fauna will be well protected through conservation education.

Different skills training to promote local arts and heritages are promoting there. It follows Integrated Conservation and Development Approach (ICDA). It has different drives / thrusts from district to district. In Lamjung, the project emphasizes on agro-livestock based program (NTNC, 2007). However, Arjun Gurung, chairman, Marshyandi Rural Municipality argues that despite the high expectation over ACAP, it could not be still effective to generate public awareness to local people as possible. Similarly, he further argues there are also some conflicts over the rights of local levels such as rural municipalities, community forest groups etc. and ACAP itself as the view of Nash (1981) which is also accepted by Prem Ghale, Chairman of Klosothar Rural Municipality. However, Mr. Ghale made clear that such types of minor issues can be solved through mutual dialogues soon. Further Kamsarki Gurung, Khanigaun adds that jungle firing is found even ACAP areas. Hence, it is still a genuine issue there.

Aama Samuha (women's group) is organized in every community. The hospitality to the new guest of the Ama Samuh with garland and evening dancing makes further extension of tourism in the district. Paying guest system to each household has been recently practicing in its working areas. Gender balance is also basic component of ACAP. Women are mobilized appropriately. Hotel and restaurants are available in each part of the district. It is also expected that ACAP will be more useful for creating awareness in nature conservation including local cultural heritages in future. INGO, $\mathrm{NGO}$ and $\mathrm{CBO}$ are performing various activities for tourist sector also however local people cannot still get adequate opportunity for employment and income as expected.

Tourism Impacts- Anthropology and tourists are closely related fields. At the one side, tourist is the one of the important anthropological source who visits different places and can observe and collect the data and information of his/her concern and share with others and anthropologists can study various components of tourism including its impacts from donor to recipient at the other (Seymour-Smith, 1986; Burns, 2004; Stronza, 2001). Therefore, they support each other. In this context, we can study the impacts of tourists after their arrival in Lamjung specially Besishar to Manang route in general.

Having many potentialities of tourism in the district, Ram Kumar Shrestha as local entrepreneur and key informant argues that star hotel, lodge and restaurants have begun to set up in the trekking routes from Dumre, a link point to Lamjung in Prithwi Highway to Manang. People can be involved in tourism as guides, cooks and porters for employment. For the prosperity of tourism, tourist information centre is essential which supports in providing visitors to locations with information on the area's attractions, lodges, maps and other related supports in this field. 
The centre is established in Besishahar. Being the areas of Annapurna tour and trekking, EuroAmericans, Chinese and Indian tourists have begun to visit there especially Manang, Thorong La pass to Mustang and Pokhara. Later, the link road from Dumre to Besishar is built as metallic. Consequently, the trekking was displaced from Dumre to Besishahar, however tourists began to travel in Besishahar from Kathmandu and Pokhara by bus with night stay at Besishahar. Some new tourist trekking routes are begun in Lamjung. They are from Besishahar - Baglungpani Bhorletar, Besishahar - Bhulbhule- Manang, Phalekhsaghu - Chiti- Barahi Pokhari to base camp and other areas.

Despite such status, tourism has both positive and negative impacts in the district. Some of the positive impacts are to increase job and income, to develop business through hotel, lodges, restaurants, wholesale and retail shopping centres, new tourist points, construction of some infrastructure, rural markets and so forth. Ironically, tourism has negative impacts also- some matured western tourists show their vested interest to impose Christianity to simple and general Nepali people. With the feeling of imitation of developed culture, Nepali indigenous cultures have began discarded. Hence cultural tourism needs to be developed for the promotion of local cultures and arts. Despite the positive and negative impacts of tourism as the views of Seymour -Smith (1986) and Burns (2004), some other local key informants and community leaders (most of the chairmen and mayor of the route) argue that no material impacts is found negatively because most of trekkers and travelers as tourists visiting in this area are found earlier oriented on the basic norms of tourism. Hence, they have brought less negative impact to us. In reality, a detail study focusing to tourist routes is very urgent to find out its practical and behaviour impacts.

\section{Prosperous and Challenges}

Historically and culturally, Lamjung attracts tourist sector. Baudh, Himchuli and Lamjung mountains are smiling in northern parts to attract the tourism. Along with Dumre to Besishahar and Manang, some small tourist routes for tour and trekking have been growing. The initial concept of home-stay in Ghalegau has been transferring in other village/areas. Some standard hotel, lodge and restaurants along with tourist infrastructures have been day to day developing there. These are the positive aspects. Nevertheless there are still some challenges existing in the district. Government still could not develop effective policies to promote entrepreneurship in tourism in the country. Modern star hotel and restaurant in tourist site and other infrastructures are still in lower number and quality. Despite the potentiality of tourism sector in the district, the efforts for searching new trekking routes have not been found any systematic planning. The local key informants remark that it is possible to find out the new trekking routes in some tourist sites such as Champabati (Chepe) riverside to Dudhapokhari following north east side of Lamjung, Baishjagare- Kalitmati- Rainaskot- Gauda- Lipe to Lamjung, Baudha and Malasulu Himals, Bhorletar - Pasgaun to Dudhapokhari, Phalekhsagu- Chiti- Baraipokhari to Lamjung and Himchuli Himal. Writing and research based activities about the different aspects of Lamjung are also nominal. Trainings, education and motivation in various sectors of tourism are also urgent. Discarded and endangered traditional and cultural heritages have to be protected and promoted with the help of government, NGO and $\mathrm{CBO}$ as the concept of cultural tourism. Behinds, 
education, awareness creation in the fields of the cultural heritage protection, hospitality have to be organised from time to time in government and private levels in Nepal..

\section{Conclusion}

Tourism has developed arts, cultures, traditional and historical heritages in the country. The prosperity through tourism in Lamjung District has been proved by the quantity and quality of adequate cultural and natural heritages from snowline in the north to narrow valley in the south. Traditionally, the Gurungs, the Ghales and the Bhote people used to enjoy life by adopting at the top of hill followed by mixed settlement of Brahmin, Chhetri, Gharti, Sanyashi and Dalit in mid hill and the Kumal and the Majhi including Chepang people in the narrow valley of the bottom parts of the hill. At present, mixed settlement are widely practised in the district. In the narrow valley like Besishahar, Bhotewadar, Tinpiple, Sundarbazar, Sotipasal, Bhorletar, small and middle size urban settlements have been flourishing gradually. Considering such conclusion, detail study on the potentiality through tourism and its impacts can be planned and executed by administrating ethnographic method as the view of Smith,1980; Burns, 2004.

Natural flora to faunas to diverse types of settlement patterns can attract to tourists. Various types of flora and fauna are also found throughout the district of Lamjung. The cultural practises are diversified from Gurung to Brahmin, Dalit to Kumal people and from hilltop to hill bottom. One can enjoy with different type of rural settlement, climate, forest, cropping patterns, and riverside and narrow valley in the district. After implementing ACAP, it is expected that various type of potentiality in tourist sector will be planned and extended. However, it could not be able to create awareness even against jungle firing in its working areas as possible though it has the goal to implement ecotourism model as Stronza (2001).

Tourism has been smokeless industry to support income and employments. As a result, active and qualified youths of the district would employ in different sector of tourism industry. The tourist entrepreneurs can produce local goods in the tourism market and improve their economy. Local arts and heritages will be then preserved. These products can also find market beyond the district (Sharma, 1995). The history of tourism in Lamjung was initiated in 1985 and gradually extended now. It has positive and negative impacts as the view of Seymour -Smith (1986) and Stronza (2001) though it has provided main economic opportunities to the people of Nepal in broader perspective.

\section{References}

Bhatta, B. N. (1999). The Duras: An original ethnic Group of Lamjung. Apsara from Gorkhapatra Sansthan. p. 4-7.

--- (1995). Adaptive strategies of the Kumals: A case study of Chakratirth, Lamjung (Unpublished Dissertation for MA Degree to TU), p. 31.

Bista, D.B. (1994). People of Nepal. Kathmandu: Ratna Pustak Bhandar,

Burns, G.L (2004). Anthropology and tourism: Past contributions and future theoretical challenges. Anthropological Forum. Retrieved from https://www.researchgate.net/.../29456605_ Anthropology_and_Tourism_Past_Contribut 
Central Bureau of Statistics. (2014). Population Census 2011. Thapathali, Kathmandu.

Department of Irrigation. (2005). Office Statistics. Lalitpur.

ICIMOD. (1997). Lamjung district information system for local planning assessment of natural resource using GIS and RS Technology. (p .3-17). Kathmandu: ICIMOD.

Kuwar, R. R. (2006). Tourists and tourism science and industry interface. Kathmandu: International School of Tourism and Hotel management, p. 114-120.

--- (2002), Anthropology of tourism: A case study of Chitwan Sauraha. New Delhi: Adroit.

Messerschmidt, D.A. (1978). Dhikurs: Rotating credit associations in Nepal. In Himalayan Anthropology: The Indo-Tibetan Interface. James F. Fisher. Ed. (p 141 -165). The Hague, Paris: Mouton.

Montero, C G. (2014). Tourism Retrieved from www.oxfordbibliographies.com/view/document/ obo.../obo-9780199766567-0025.x

MoTCA. (2009) Nepal tourism statistics: Kathmandu. pp. 6-9.

Nahman, M R. (2016). Reproductive tourism: Through the anthropological "Reproscope". Retrieved at: November 1, 2017, from http://www.annualreviews.org/

Nash, D.C. (1981). Tourist as anthropological subject. Chicago: The University of Chicago Press. Retrieved from https://www.jstar.org/stable/2742284.

National Trust for Nature Conservation. (2007). Office Statistics and Records. Kathmandu.

Seymour- Smith, C. (1986). Macmillan dictionary of anthropology. London: Macmillan.

Sharma, P.R., (1995). Culture and tourism defining roles of and relationship. The Discussion Paper Series No. MEI 95/2. Kathmandu: ICIMOD.

Smith, V. L., (1980). Anthropology and tourism. The Annals of Tourism Research VI (I). US of America. p. 15.

Stronz, A. (2001). Anthropology of tourism: Forging new ground for ecotourism and others Alternatives. Retrieved at: 29October, 2017, from http://www.annualreviews.org/

Thapa, K.B. (2007). Lamjungko Itihas ra Sanskriti Sambandhi Ek Charcha, A paper presented in a workshop organized by Lamjung Literary Society in Valmiki Vidhyapith, Kathmandu, p. 2-3. 
Annex-1

Table 2: Population by Caste/Ethnicity in Lamjung District

\begin{tabular}{|l|l|c|c|c|c|}
\hline \multirow{2}{*}{ S. No. } & Caste/ & Male & Female & Total & Percentage \\
\cline { 2 - 3 } & Ethnicity & 23552 & 28869 & 52421 & $31.25 \%$ \\
\hline 2 & Gurung & 11714 & 15109 & 26823 & $15.99 \%$ \\
\hline 3 & Chhetri & 9673 & 11713 & 21386 & $12.75 \%$ \\
\hline 4 & Hill Brahmin & 6572 & 7902 & 14474 & $8.63 \%$ \\
\hline 5 & Kami & 5646 & 6475 & 12121 & $7.23 \%$ \\
\hline 6 & Tamang & 3571 & 4938 & 8509 & $5.07 \%$ \\
\hline 8 & Sarki & 3053 & 3546 & 6599 & $3.93 \%$ \\
\hline 9 & Newar & 2901 & 3322 & 6223 & $3.71 \%$ \\
\hline 11 & Gharti/Bhujel & 1755 & 2072 & 3827 & $2.28 \%$ \\
\hline 10 & Magar & 1841 & 1916 & 3757 & $2.24 \%$ \\
\hline 7 & Dura & 1354 & 1805 & 3159 & $1.88 \%$ \\
\hline 14 & Kumal & 760 & 939 & 1699 & $1.01 \%$ \\
\hline 13 & Thakuri & 730 & 875 & 1605 & $0.96 \%$ \\
\hline 12 & Dashnami/ Sanyasi & 612 & 720 & 1332 & $0.79 \%$ \\
\hline 15 & Others & 1516 & 2273 & 3789 & $2.26 \%$ \\
\hline Total & & $\mathbf{7 5 2 5 0}$ & $\mathbf{9 2 4 7 4}$ & $\mathbf{1 6 7 , 7 2 4}$ & $\mathbf{1 0 0 . 0 0 \%}$ \\
\hline
\end{tabular}

Source: Population Census, 2011 